This is the pre-peer reviewed version of the following article : Resolving Coparenting Dissatisfaction In Couples: A Preliminary Task Analysis Study, Eira Nunes C., Pascual-Leone A., Roten Y., Favez N., \& Darwiche J. (2020). Journal of Marital and Family Therapy. Advanced online publication. doi : 10.1111/jmft.12450, which has been published in final form at https://doi.org/10.1111/jmft.12450. This article may be used for non-commercial purposes in accordance with Wiley Terms and Conditions for Use of Self-Archived Versions.

\title{
Resolving Coparenting Dissatisfaction In Couples: A Preliminary Task Analysis Study
}

Cindy Eira Nunes ${ }^{1}$, Antonio Pascual-Leone ${ }^{2}$, Yves de Roten ${ }^{1}$, Nicolas Favez ${ }^{3}$, and Joëlle Darwiche $^{1}$

\author{
${ }^{1}$ University of Lausanne, Switzerland \\ ${ }^{2}$ University of Windsor, Canada \\ ${ }^{3}$ University of Geneva, Switzerland
}

Acknowledgment: This work was supported by the Swiss National Science Foundation under the Grant SNF 159437.

Correspondance to: Cindy Eira Nunes, IP-SSP Géopolis, Université de Lausanne, CH1015 Lausanne, email: cindy.eiranunes@unil.ch 


\begin{abstract}
This paper explored the change process unfolding when parents resolved their coparenting dissatisfaction during an Integrative Brief Systemic Intervention (IBSI) for parent couples. We conducted a task analysis (Greenberg, 2007) to build a model of resolving coparenting dissatisfaction. We compared a postulated model of change (rational model) based on clinic and theory to the observations of the actual change process that couples experienced in IBSI (empirical analysis). An empirical analysis was conducted on six IBSI therapy cases (three exhibiting positive development and three exhibiting no development). We defined positive development in IBSI as moving from coparenting dissatisfaction to coparenting satisfaction. The final rational-empirical model included six process steps that featured in the resolution of coparenting dissatisfaction. This study contributes to deepening our knowledge on how coparenting may change during marital therapy.
\end{abstract}

Keywords: coparenting, marital therapy, parent, task analysis 
Resolving Coparenting Dissatisfaction

In An Integrative Brief Systemic Intervention for Parents: Task Analysis

Parent couples are bound to each other by both a romantic relationship and a coparenting relationship (Favez, 2013). The romantic relationship engages the individuals as partners, whereas the coparenting relationship engages the individuals as parents. Coparenting has been defined as the coordination among the adults responsible for the care and upbringing of a child (McHale \& Irace, 2011). In a systemic-structural perspective, these relationships have been considered as two functional subsystems, distinct from one another, but deeply interrelated (Minuchin, 1974). Therefore, both relationships should be considered in therapeutic work with parent couples (e.g., Stroud, Meyers, Wilson, \& Durbin, 2015; Zemp, Johnson, \& Bodenmann, 2018). In this paper, we focused on the importance of the coparenting relationship. We explored the process unfolding when parents worked on this relationship in specific marital therapy, using the task analysis method (Greenberg, 2007).

The literature has supported the pivotal role of the coparenting relationship. Empirical findings have supported the association between the quality of coparenting and romantic relationships (e.g., Durtschi, Soloski, \& Kimmes, 2017; Morrill, Hines, Mahmood, \& Cordova, 2010; Schoppe-Sullivan, Mangelsdorf, Frosch, \& McHale, 2004). High-quality coparenting featuring cohesion, cooperation, and support has appeared to be positively associated with marital satisfaction (Favez \& Frascarolo, 2013; Talbot \& McHale, 2004), whereas low cooperation between parents and high competition have been associated with romantic conflicts and dissatisfaction (e.g., Christopher, Umemura, Mann, Jacobvitz, \& Hazen, 2015). Coparenting has also appeared to mediate the effect of the romantic relationship on parenting. Pedro, Ribeiro, and Shelton (2012) have found marital satisfaction to be a predictor of decreases in coparenting triangulation and conflict, as well as an increase in cooperation, which in turn was associated with fewer negative parenting behaviors, such as 
rejection and control attempts. These findings have supported the growing literature on the spillover effect between the romantic and the coparenting relationships (Bonds \& Gondoli, 2007; Stroud et al., 2015). The spillover effect implies that the emotions that an individual experienced in a relationship influence other relationships (Kitzmann, 2000). Finally, the coparenting relationship has been largely presented as being of paramount importance for the child's development (see the meta-analysis by Teubert \& Pinquart, 2010).

Interventions that target coparenting have appeared critical for creating changes that have substantial effects within the family system and, thus, a growing number of prevention programs have offered coparenting-based interventions (e.g., Barton et al., 2015; Feinberg et al., 2016; Florsheim et al., 2012). Numerous randomized controlled trials on coparentingbased programs have demonstrated evidence of their efficacy to enhance family well-being, by improving individual's well-being (e.g., Feinberg et al., 2016) and relationship quality (e.g., Barton et al., 2015; Florsheim et al., 2012). Whereas these studies documented the relevance of targeting coparenting within prevention, in this paper, we have studied the effects of targeting coparenting relationships within a specific intervention for distressed parent couples, the Integrative Brief Systemic Intervention (IBSI).

The IBSI is a manualized treatment provided to parent couples that targets both romantic and coparenting relationships (Carneiro et al., 2012). The intervention is brief, six sessions in about six months. We divided it into three phases: the initial phase (session 1), the intervention phase (sessions 2 through 5) and the final phase (session 6). The purpose of the initial phase is to co-construct the therapy framework and define the problem that led the couple to start therapy. In this phase, the therapist and the couple work together to set concrete objectives achievable within the brief timeframe of their therapy. Subsequently, the intervention phase corresponds to the therapeutic intervention itself. The therapist uses numerous techniques and treatment approaches, such as the structural, strategic, and 
transgenerational models (Bowen, 1984; Haley, 1963; Minuchin, 1974; Selvini, 1987), to address the couple's issues and achieve the objectives set in the initial phase. The final phase is a wrap-up session that allows both the therapist and the couple to reflect on the therapy process and determine if they will end treatment or continue with additional sessions. To maximize the mobilizing effect of the limited therapeutic timeframe, each session starts with the clients' feedback on their experience of the previous session in terms of the therapy process and therapeutic alliance (Macaione, Darwiche, Fasseur, \& Vaudan, 2018).

Three central ideas have supported this integrative model of therapy. (1) Both the romantic and coparenting relationships are crucial to parent couples' functioning and their improvement induces a process of generalization resulting in various changes at different family levels (e.g., parent-child and individual levels). (2) Focus on the coparenting relationship increases couples' awareness of how their difficulties have affected their children. (3) Parents are more motivated to change if it is for their children's well-being.

\section{Task Analysis}

The task analysis is a method that has been applied to psychotherapy research to study the process of change, such as an examination of steps by which clients' resolving a specific emotional-cognitive problem during treatment (Greenberg, 2007). Specifically, this method is used to elaborate a temporally ordered model of changes that lead to the resolution of a specific task. Task analysis typically focuses on the client processes that lead to change, while the role of the therapist is put into the background and reserved for later developments in a program of research. The rationale for this methodological approach is to focus on the pathways toward resolution, leaving the facilitation of those pathways (i.e., the role of the therapist) as a research question to be addressed by later inquiries.

Task analysis begins with a discovery phase structured in four steps: (1) definition of the task under study, which specified the basic unit and context for the process analysis that will 
follow; (2) construction of a rational model that is based on a review of relevant literature and postulates on the theoretical steps involved in task resolution; (3) an empirical analysis of therapy sessions to observe clients' (in this case couples') actual experiences of the task; and (4) a rational-empirical model, which synthesizes both theoretical and observational findings from steps 2 and 3. A later phase of task analysis typically includes an empirical validation of the model that was developed (for further details on the research method see Pascual-Leone, Greenberg, \& Pascual-Leone, 2014). In the present study, we focused on the third and fourth steps of the discovery phase as we have preliminary conducted the first two steps (presented below).

Definition of the task. Defining the task involves identifying a problem state that eventually gets solved in therapy, as well as delimiting that task with a beginning and an end. We refer to the beginning and the end of the task as the task marker and the resolution marker, respectively. Our task analysis focused on work being done by couples, such that both members are needed to contribute to the resolution of a shared task: That task was resolving coparenting dissatisfaction in the IBSI. The task marker corresponded to coparenting dissatisfaction and the resolution marker to coparenting satisfaction.

Rational model. As the method prescribes, we built a rational model that postulates a theoretical sequence of steps through which couples pass in resolving their coparenting dissatisfaction in therapy. Our rational model articulated the clinical hypotheses underlying the IBSI model (Carneiro et al., 2012) and the theoretical assumptions drawn from attachment and systemic theory. Expert assumptions within the IBSI treatment model and on marital therapy more broadly oriented our choice of this specific framework. Parents first needed to work on their insightfulness to increase their awareness of the children's experience of facing parents' difficulties ( $1^{\text {st }}$ process step). Their concern for their children may have facilitated their engagement in a shared objective. This mutual engagement could then have enhanced 
the development of we-ness ( $2^{\text {nd }}$ process step) as parents worked together for their children's well-being. This two-step model moved couples from the task marker to the resolution marker.

Insightfulness ( $\left(1^{\text {st }}\right.$ process step). Insightfulness is drawn from the attachment literature and corresponds to the mental process underlying parents' caring behaviors (e.g., Koren-Karie, Oppenheim, Dolev, Sher, \& Etzion-Carasso, 2002). It can be defined as a parent's capacity to adopt their children's perspective (Oppenheim \& Koren-Karie, 2002). It comprises three principal components: (a) insightful parents try to empathically understand the motives for their child's behaviors in terms of thoughts and emotions; (b) a complex view of the child underlays the parents' attempt to understand the motives of the behavior of the child, whom they perceive as an independent individual, different from the parents, with both qualities and flaws; (c) the last component involves the parents' openness regarding his or her view of the child. Parents are thus willing to challenge their view of the child. Moreover, they can adapt their understanding of the child's emotional experience and thoughts according to new information (Koren-Karie et al., 2002). Studies have predominantly focused on maternal insightfulness (e.g., Oppenheim, Goldsmith, \& Koren-Karie, 2004; Oppenheim \& KorenKarie, 2002). However, Marcu, Oppenheim, and Koren-Karie (2016) reported that both parents' insightfulness was necessary to ensure high quality coparenting.

The relevance of insightfulness is also clinical. Insightfulness is one of the main principles of the IBSI, which engages the couple as parents, stressing the impact of their problems on their children. Regardless of the couples' reasons to seek therapy, shared concerns for their children are a resource for therapy because parents might be more willing to work together if it is for their children's well-being. The rational model we have used in the present study suggests that working on insightfulness facilitates the development of we-ness, while parents increase their commitment to the coparenting relationship. 
We-ness ( $2^{\text {nd }}$ process step). The concept of we-ness refers to the identification of the self as part of a relational dyad. Partners perceive the couple itself as a higher-order unit, rather than the summation of two independent individuals (Buehlman, Gottman, \& Katz, 1992). It reflects the interdependence between partners, rather than the fusion of two individuals into one undifferentiated or monolithic entity (Skerett et al., 2005). We-ness implies that parents can address their differences and connect to one another despite these differences. As a reflection of this unity, couples will often refer to the dyad using "we" and "us" language (Skerrett, 2015). Researchers have demonstrated that we-ness, observed in exchanges between partners either in interviews or in therapy, predicts marital satisfaction (e.g., Buehlman et al., 1992; Reid, Dalton, Laderoute, Doell, \& Nguyen, 2006) and facilitates couples' interactions (e.g., Seider, Hirschberger, Nelson, \& Levenson, 2009). Couples with a high level of we-ness were calmer and expressed more positive affect during conflict discussions compared to couples with low levels of we-ness (Seider et al., 2009).

In summary, we postulated that these two process steps - insightfulness and weness - are directly involved when parents manage to successfully resolve their coparenting dissatisfaction and both identify and experience themselves as a coparenting entity (the resolution marker). Together they represent the rational model, and the theoretical framework for interpreting observations in the following steps of our task analysis: the empirical analysis (step 3) and the rational-empirical modeling (Pascual-Leone et al., 2014).
Aim
Through task analysis, we aimed to inform on the step-by-step changes occurring within sessions. Although particularly relevant and informative for both research and clinic, task analysis studies have remained few in marital therapy research (Bradley \& Furrow, 2007; Heatherington \& Friedlander, 1990; Woldarsky Meneses \& Greenberg, 2011). In addition, to our knowledge, researchers have not explored coparenting-related processes. Consequently, 
this study has contributed to deepening our understanding of an overlooked process unfolding in marital therapy and has offered first insight on the collaborative work between partners when trying to resolve a distressing situation together.

The building of a synthesized rational-empirical model to describe the process of resolving coparenting dissatisfaction as experienced by couples that resolve the task (resolved couples) compared to couples that did not (unresolved couples) is the principal goal of this paper. It resulted from the combination of the rational model (described above) with empirical observations, based on the actual process as observed within sessions.

\section{Method}

\section{Sample}

We drew the six couples analyzed in this study from an ongoing randomized controlled trial (RCT) on the efficacy of the IBSI, a project financed by the Swiss National Science Foundation (SNF 159437). At the time of the analysis, the RCT sample comprised 18 couples having completed the IBSI from which we selected six couples, as suggested by the task analysis method (Pascual-Leone et al., 2014). To be eligible, couples had to express coparenting dissatisfaction (task marker) within the first five sessions (see the procedure section for details). Among our sample of six couples, the 12 participants were in their forties $(M=40.6, S D=4.8$; ranging from 35 to 50 years old $)$ and had pursued higher education $(9 / 12$ participants had a university degree). All couples were heterosexual and in a relationship for an average of 10 years $(M=9.8, S D=5.9)$. They had one to four children and, on average, the youngest child was almost four years old $(M=4.2, S D=3.6)$. Two families were stepfamilies. Couples sought therapy after an average of almost two years of relational difficulties ( $M=23.9$ months, $S D=22$ months). The six selected cases were paired, in the sense that resolved and unresolved couples sought therapy for similar reasons. Two couples sought therapy for infidelity, two others for pervasive conflicts in front of the children, and, finally, 
the last two couples reported issues related to the relationship between stepparent and stepchild. Among each of these sets of couples, one was resolved, whereas the other was not.

\section{Material}

We analyzed six therapies of six sessions per couple, except for one (resolved) couple that only went through five sessions. Among the six therapies, one course of treatment only had four recorded sessions out of six (a resolved couple), where sessions 2 and 5 were not available. Nevertheless, this therapy met the selection criteria (detailed below) as the task marker and the resolution marker could respectively be identified in the first and sixth sessions. The total sample of analyzed sessions included 33 therapy sessions; each session lasted from 60 to 90 minutes; 21 sessions were videotaped and 12 were audiotaped sessions.

Self-reported questionnaires were administered to couples before and after the intervention to assess four outcome levels: individual, romantic, coparenting, and family levels. The RCT included questionnaires on individual symptomatology (OQ, Lambert, Fintch, Okishi, \& Reisinger, 2005; STAI-Trait, Spielberger, Gorsuch, Lushene, Vagg, \& Jacobs, 1983; PHQ, Spitzer, Kroenke, Williams, \& Group, 1999); on marital satisfaction (DAS, Spanier, 1976) and dyadic coping (DCI, Bodenmann, 2008); on coparenting support (PAM, Abidin \& Konold, 1999; PCPQ, Strigth \& Bales, 2003) coparenting conflict, and triangulation (PAFSQ, Bray, Williamson, \& Malone, 1984; CIPA, Teubert \& Pinquart, 2011); as well as on parental sense of competence (Being a Parent, McCarty \& Doyle, 2001) and family functioning (FAD, Epstein, Baldwin, \& Bishop, 1983).

\section{Empirical Analysis}

Operationalization of the task and cases selection. The task was described in terms of observational cues characterizing the task marker and the resolution marker. The task marker was signaled by verbal and para-verbal cues of negative emotions, such as sadness, anger, irritation, helplessness, etc., expressed by one parent (at least) regarding the other as a 
coparent or the coparenting relationship. The resolution marker corresponded to both parents expressing positive affect regarding their coparenting relationship. Verbal and para-verbal cues of positive emotions, such as for example joy, relief, satisfaction, or hope, had to be observed from both parents regarding the coparenting relationship. Furthermore, for the task to be considered resolved, parents had to refer directly or indirectly to their dyad functioning as a "collaborative team" (e.g., when referring to an episode when one parent was able to support instrumentally and, or emotionally the other parent).

The discrimination between resolved and unresolved cases was based on the observations made during the last session. To confirm the resolution, both partners needed to express positive affect regarding their coparenting relationship. To support this discrimination further, outcomes were investigated. For resolved cases, we identified positive changes from pre- to post-intervention on at least two levels out of the four we measured (i.e., individual, romantic, coparenting and family levels). By contrast, the results of unresolved cases were heterogeneous. Two cases displayed few positive changes from pre- to post-intervention because only one level out of four improved for only one of the partners. Results on the other levels were either stable or had decreased. Surprisingly, the last couple from the unresolved cases was characterized by changes in outcomes although the resolution marker was not identified in the last session. Observation of the last session clearly indicated no improvement in the couple's dynamic. Partners even reported the following in the last session: "these sessions did not help us (...) maybe it wasn't the right time to engage in therapy." At the beginning of therapy, these partners presented overt destructive conflicts but progressively appeared to avoid conflict. This change in conflict management may have induced the minimization of difficulties that may explain the pseudo-changes in the questionnaires.

Delimiting the scope of process analysis. The analysis started when one parent expressed negative affects regarding the coparenting relationship (the task marker) to the 
resolution marker, in which both parents expressed positive affect regarding the coparenting team (or to the end of the last session if no resolution marker could be identified). Among those couples who reached it, the resolution marker was always found in the last session.

Coding sessions. For each case, the first author identified events related to insightfulness, coparenting we-ness (two process steps of the rational model), and to coparenting more broadly to identify events that were not covered by the rational model. Each identified event was then described in terms of verbal and para-verbal cues.

For each analyzed case, description of unspecified events was screened to identify similar events and pool them under a new common label more specific, such as "complaints towards the other parent" or "validation of the other parent". Pooling similar events under the same label aimed to minimize the number of new process steps, as each new label could correspond to a new step of the emerging model. We then organized and summarized each couple's sequence of events to tell the story of their progress from coparenting dissatisfaction to coparenting satisfaction. We called it the couple's overarching story, which summarized the critical events that featured the couple's experience of the task through the course of therapy.

\section{The Final Rational-Empirical Model}

The final step of our study was to build the synthesized model of change based on the six overarching stories resulting from our analysis. We first compared the cases to identify the observed process steps necessary to resolve the task. Following methods outlined by PascualLeone et al. (2014) we integrated these findings based on observation to our initial rational model.

Cases comparison. First, we compared the resolved cases to identify similarities and synthesize a process common to the three resolved cases. Subsequently, we contrasted the resolved cases' process with the processes that the unresolved cases had experienced. We 
judged a process step as unnecessary for resolving the task if all cases had experienced it, and if it did not appear to be an antecedent requirement for later steps that did indeed distinguish between groups. The similarities between resolved cases, as well as the disparities between the resolved and unresolved cases, allowed us to identify the essential process steps of resolving coparenting dissatisfaction.

Synthesizing theory and observations. To ensure articulation between theory and observations, we first verified that insightfulness and we-ness (presented in the rational model) were essential process steps as they were present for resolved couples and absent for unresolved couples. Secondly, we clarified to what extent new steps featured the couples' progress. We integrated the essential new steps we identified through the cases comparison in the initial rational model. This process of comparing the empirical findings with the rational model allowed the development of a synthesized rational-empirical model that integrated observations of the couples' performances within a defined theoretical framework.

\section{Results}

The analysis of the three resolved couples supported the relevance of the rational model that we presented previously. Both insightfulness and we-ness appeared as crucial process steps in the change process. However, in our analyses, we identified four additional process steps necessary to resolve coparenting dissatisfaction (Figure 1): "awareness of coparenting dissatisfaction," "reflecting on negative coparenting dynamics," "innovation," and "validation." Some process steps were featured by the involvement of both parents and others not necessarily. When they engaged only one parent, process step resulted in this parent becoming more engaged in the change process than the other was. This potential imbalance between parents did not prevent change within the couple.

Each step corresponded to a sequence of events that we systematically observed within the resolved couples' sessions. Unresolved couples tended to present some of the mentioned 
steps; however, all the couples did not systematically present the same steps. Indeed, although some unresolved couples presented one or two steps of the change process, they appeared to face obstacles preventing the resolution of the task. For example, partners of one couple were unable to reflect on their negative coparenting dynamics because they could not share their point of view. They were stuck in attack-defense exchanges. They stayed focused on their own perspective and were unable to listen and validate the other's perspective. We presented each step of the final model below, with a detailed description of its characteristics and examples of some prototypical interactions.

\section{Coparenting Dissatisfaction}

Coparenting dissatisfaction signaled the beginning of the task. Parents expressed emotions such as sadness, anxiety, hostility, and hopelessness regarding the other's attitudes or behaviors as a coparent or regarding the coparenting relationship itself. For example, in a prototypical episode of coparenting dissatisfaction, the mother said this (couple A, Session 1):

We fight a lot... [she starts crying] it's always in front of our daughter [...] For me, as long as we keep our tensions between us, I can handle it... But now, it is becoming a problem for our daughter, for the whole family. It cannot continue this way!

For some parent couples, the task marker was characterized by parents expressing their coparenting dissatisfaction and minimizing it immediately after with notable incongruence between verbal and para-verbal cues. For example, within the first session of couple B, the father was the first to express his coparenting dissatisfaction. However, he was elusive as he presented the situation as a problem, but immediately tried to minimize it by adding "sometimes," and "it's not a big deal." The para-verbal level was also incongruent with the verbal level as he appeared nervous when he explained the following:

Regarding our children, I'm never informed of anything, it can be a problem between us, sometimes... I'm always informed of what they're doing at the last minute. For 
instance, if they are sleeping over, I hear about it when they are already at their friend's house... But it's not a big deal...

\section{Awareness of Coparenting Dissatisfaction}

During this step, both parents exchanged views on concrete behaviors and/or mental states that may be the source of coparenting dissatisfaction. They formulated concrete expectations regarding the other parent. Parents expressed negative emotions, such as anger, irritation, or sadness. Both parents were engaged in the exchanges and, thus, recognized the issue under discussion. For example, still in the first session of couple A, the mother said this with a determined tone:

In my opinion, the main problem is that we act like we are enemies... For example, when our daughter disobeys me, although you should help me deal with her, you start criticizing me: 'You yelled at her again, I can't stand it when you yell...' and it becomes a topic of argument between us.

The father, annoyed, added this: You always say that I don't support you enough in front of our daughter, but it is because I disagree with you and I don't know how to support you in those moments!

Parents who at first minimized their coparenting dissatisfaction were able to share more authentically their complaints with and to formulate expectations. Regarding the previous example (coparenting dissatisfaction section, couple B), the father who was minimizing his coparenting dissatisfaction is now able in this step to address his initial complaint without trying to minimize it. Verbal and para-verbal cues were congruent as the father overtly expressed his frustration and anger regarding the situation. Indeed, in the third session, irritated, he explained:

There are two problems: first, you [his wife] make decisions regarding our children without consulting me, second, you don't tell me about these decisions. For example, 
the other night, I heard that our son was at a party when I asked where he was. You didn't tell me anything about it the day before or even earlier the same day. I only find out about those things at the last moment.

The mother argued as follows: It was decided during the day, at the last minute.

The father continued with a negative tone of voice: If he asks my permission to go out, I never give him an answer right away. I tell him we will think about it!

The mother adds this: Yes [she sighs] the problem is that you never answer, so you never decide. And when you do, I'm the one who has to handle the consequences.

\section{Reflecting on Negative Coparenting Dynamics}

Both parents reflected on their negative coparenting dynamics. This step was not characterized by any specific expressed emotions. Compared to the previous step, parents stopped exclusively blaming each other for the encountered difficulties. Instead, they developed an interpersonal awareness regarding each one's personal contribution to the negative coparenting dynamic in terms of actions and reactions to each other. The coparenting dynamic corresponded to the sequences of actions and reactions in which parents were caught (i.e., parent A is overinvested regarding childrearing leaving no room for parent B who disengaged from childrearing as a result of parent A overinvestment; in turn, parent B's disengagement reinforced parent A's overinvestment).

For the couple A, the following event occurring in the third session exemplified this step. It started with the father explaining what ensues:

We have totally different opinions, and we rarely agree regarding our daughter. I admit that it annoys me because I get the feeling that it can never be easy between us! I even anticipate that some situations will lead to an argument and thus I try to avoid them by letting you handle the situation. 
The mother validated the father and added this: The level of tension is so high that I also tend to manage by myself regarding our daughter. To avoid conflict, I only ask for your help when needed. However, it can bring frustration for me. For example, during the holidays, when you say, 'I'm just going for a walk, I'll be right back' and that again I stay with our children, I feel frustrated. As I'm frustrated, I can be aggressive because I feel that my life is more boring than yours.

\section{Insightfulness}

At least one parent increasing his/her insight into the child's emotional experiences facing the negative coparenting dynamics identified earlier was a feature of this step. The parents explored their child's perspective in a warm and accepting manner. They may also have referred to their own emotions regarding the child's experience, such as worries, frustration, pride, etc. The parents identified concrete examples of the child's reactions and tried to understand the child's motives by exploring emotions and thoughts that underlay these reactions. Parents regularly used conditional tenses and words such as "it seems," "maybe," "probably," and "I think," which reflected their openness and their willingness to possibly challenge their view of the child.

For the couple A, the mother was the one who explored more deeply her child's perspective. Indeed, in session three, she expressed this:

The other day, we [parents] were talking about school and she came between us. As she was pulling my arm, she started yelling: 'Stop now! Mommy come play with me! Come on!' [Sadly.] It looks like she thinks we are arguing even when we are simply chatting...

Some parents even used their own experience as children to reflect on their child's experience if they could stay child-focused and discriminate between their own vision and their child's actual experience. For example, in couple C's fifth session, the father 
remembered his own experience as a child and could be empathetic for his son. In the fifth session, the father said this:

Sometimes, my son wants his mother to help him and doesn't want me to take care of him. I find it unfair... [He pauses] It's true that I had myself a strong relationship with my mother and felt really close to her as a child. [He pauses again] I guess I need to let them have those moments because it's important for him to also have those motherson moments as I used to have with my mom.

\section{Innovation}

This step described how one parent, at least, voluntarily adopted new actions to overcome the negative coparenting dynamics. The parent mentioned a first attempt to act or react differently in a coparenting situation towards either the other parent or the child. Some parents also expressed some ambivalence as they encountered difficulties while trying new behaviors or as maintaining the change might be difficult. Again, for the couple A, in the last session (session 6) the mother explained the following:

Recently, I agreed to let my husband leave with our daughter for the weekend. It was the first time that they left without me. When he first suggested it, I refused! But then I thought about it and considering our discussions over sessions, I realized that I needed to let it go.

\section{Validation}

New actions by one parent were followed by the other parent validating the innovation. The parent validating the innovation attempts approved the changes. In our preceding example (couple A, session 6), the father validated saying this:

When you finally agreed to let her go with me, I was surprised, but also relieved. At that moment, something changed!

\section{Coparenting We-ness}


At the coparenting we-ness step, parents identified themselves as part of a new coparenting team progressively moving from I-language to we-language. Warmth and tolerance characterized the exchanges. Parents highlighted the positive impact of the innovation step on their coparenting relationship. For instance, the mother from couple A explained this to her husband in the sixth session:

I realized that I'm able to let go and let you handle our daughter on your own. [Excited.] That is huge! ... When I leave work, I'm no longer in a hurry to get home because I know that you're taking care of our daughter and that everything is all right, even if I'm not there.

However, some parents also addressed the persisting difficulties in maintaining the new positive coparenting dynamics and accepted each other's different viewpoints. The father (couple A, session 6) shared his understanding of their new dynamic:

We still have different opinions on a lot of child-related topics. However, in our team, we have a specific dynamic implying that at times we should insist on our own opinion and ant times let the other do his or her way...

\section{Coparenting Satisfaction}

Finally, we observed that parents resolved their coparenting dissatisfaction by expressing their satisfaction regarding both the coparenting relationship and the other as a coparent. Both coparents expressed positive emotions, such as joy, relief, and acceptance. They referred to the coparenting relationship using we-language. For instance, the mother in couple A sounded relieved as she concluded with this:

We have made a lot of concrete efforts to be more of a team towards our daughter.

Now we can rely on each other and deal with everyday situations together.

The father validated: Yes, I agree. I also feel it's easier between us now!

Moreover, the couple $\mathrm{C}$ resolved the task when the mother said this: 
I feel that we progressed a lot regarding how we manage our disagreements in front of our son. We are on the same page most of the time.

The father added the following: Sometimes when we are tired and inattentive, we contradict each other in front of our son, but $90 \%$ of the time we are consistent. And it really works, he listens to us.

\section{Discussion}

Our observations supported the rational model because the three resolved couples developed insightfulness and coparenting we-ness during the sessions, contrarily to the unresolved couples that did not. The exploration of resolved and unresolved couples' sessions (empirical analysis) also revealed the role of four new process steps for the resolution of coparenting dissatisfaction (i.e., coparenting dissatisfaction, reflecting on coparenting negative dynamics, innovation, and validation). Our results agree with those of previous task analysis studies by researchers who could enrich their rational model by using observations of the actual process within sessions (e.g., Aspland, Llewelyn, Hardy, Barkham, \& Stiles, 2008; Woldarsky Meneses \& Greenberg, 2011; Zuccarini, Johnson, Dalgleish, \& Makinen, 2013).

Our synthesized six-step model appears to highlight the importance of the pivotal psychotherapeutic concept of insight, which may be defined in marital and family therapy as new or changed understandings of one's own or others' behaviors, emotions, and cognitions (Heatherington \& Friedlander, 2007). It is a broader concept than that of insightfulness, which was used in this study and which specifically refers to the parent's understanding of his or her child's perspective (Oppenheim \& Koren-Karie, 2002). In our model, work on insight characterizes five of the six steps. These steps are as follows: (step 1) awareness on coparenting dissatisfaction; (step 2) reflecting on negative coparenting dynamics; (step 3) insightfulness; (step 4) innovation; and (step 6) coparenting we-ness. In step 1, parents first developed insight into themselves as they explored their own coparenting dissatisfaction. 
Then in step 2, they tried to clarify how they were acting and reacting to one another. This contributed to both parents' insight into the coparenting subsystem. In step 3, when exploring the child's perspective, parents worked on their insight into the child specifically. In step 4, parents were able to realize how some innovations could positively affect the coparenting dynamics. They thus appeared to reinforce their insight into the new coparenting dynamics. Finally, in step 6, coparenting we-ness implied insight into the other and the self within the coparenting team, as parents realized how they were able to integrate the other's point of view and form a coparenting team despite their different points of view and emotional experiences (Fergus \& Skerrett, 2015; Reid et al., 2006). These observations are in line with those of other researchers who underlined that insight into the self (e.g., how am I?), as well as the other (e.g., how is my partner? how is my child?) and the system (e.g., how are we together, my partner and I?) (Heatherington \& Friedlander, 2007) characterize marital therapy. In addition, in his qualitative meta-analysis, Timulak (2007) revealed that patients, when asked about what was helpful in therapy sessions, frequently recalled that insight was helpful. Insight is,

furthermore, considered a common factor in psychotherapy (Benson, McGinn, \& Christensen, 2012; Wampold, Imel, Bhati, \& Johnson-Jennings, 2007). Research has demonstrated that the therapy approach did not predict the level of insight patients reported (McAleavey \& Castonguay, 2014).

\section{Clinical Implications}

So far, researchers have overlooked coparenting both as a target and as an outcome of therapy. To our knowledge, no prior study has explored the change process unfolding when parents work on their coparenting relationship during marital therapy. This study was a first step in establishing the relevance of working on the coparenting relationship during marital therapy. Therapeutic work on the coparenting relationship may be not only relevant in an intervention such as IBSI, but also in more traditional marital therapy with parents. 
Our synthesized rational-empirical model sheds light on therapeutic work with parents and, therefore, may enrich marital therapists because it maps the essential steps as well as potential pitfalls for couples to overcome their coparenting dissatisfaction. This model also highlights the importance of both parents' involvement in the change process. Although the level of engagement may not be equal between parents, in the end, both parents must be engaged in the process to reach coparenting we-ness and reinforce their coparenting team through collaboration. The therapists should thus pay attention to each parent's engagement, but also be aware that one parent may be less engaged in the process than the other may, and that this does not necessarily prevent the couple from resolving the task. Finally, because of the spillover effects between the coparenting and romantic relationships (Stroud et al., 2015), progress in the resolution of coparenting dissatisfaction may then positively affect other relationships, such as the romantic one. The benefits of this change process are thus potentially beyond the coparenting satisfaction.

\section{Limits}

This study explored the change processes within therapy sessions. External factors, such as stressful events between sessions or being simultaneously in marital and in individual therapy, were ignored. It could not be excluded that external factors influenced the change process by preventing unresolved couples from resolving the task or, conversely, by precipitating a resolution for resolved couples. For example, it appeared that relationship duration was on average longer for unresolved couples $(M=12$ years, $S D=1.3$ years $)$ compared to resolved couples ( $M=5$ years, $S D=6.8$ years). This feature could signal that unresolved couples' coparenting dynamics were more anchored and it may thus have been more difficult for them to work on these dynamics within a brief therapy such as IBSI.

Another limit concerns the impact of the therapist. Given our couple-centered approach, our findings did not allow to inform on the importance of therapist's interventions 
for the couple's change process. Further research could thus complete our synthesized model with therapist's interventions that seemed to facilitate couples' transition from one process step to another.

\section{Future Directions}

The goal of the discovery phase of task analysis (Greenberg, 2007) is to build a model of change for a specific sample in a specific context. The validation phase on a larger sample and/or another intervention is the next necessary step to generalize our model. This phase implies using the criteria of our six-step process to code couples' change process within therapy sessions and potentially confirm the model of change that we identified in this study.

\section{Conclusion}

The discovery phase of our task analysis resulted in a rational-empirical model of resolving coparenting dissatisfaction in an intervention for parents requesting marital therapy. This synthesized model, which our observations of in-session exchanges enriched, included a six-step process of the couples' progress regarding their coparenting relationship. The task of resolving coparenting dissatisfaction appeared as an interpersonal task that requires both parents' involvement and collaboration. How therapists may address coparenting in marital therapy and how they may address changes in the coparenting relationship had major implications for both clinical practice and research. 


\section{Coparenting dissatisfaction}

(Parent $A$ and/or B)

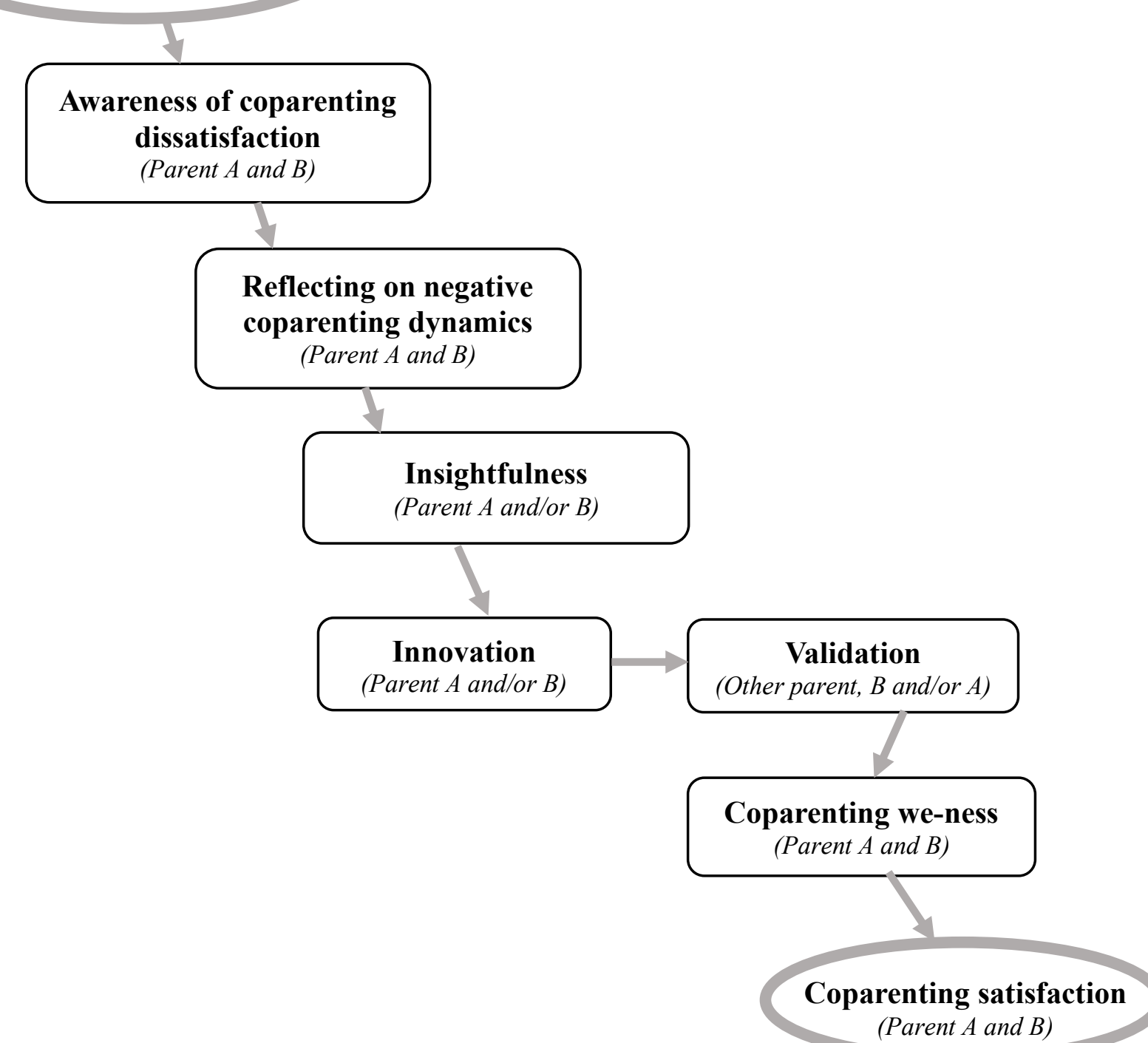

Figure 1. Rational-empirical model of resolving coparenting dissatisfaction 


\section{References}

Abidin, R. R., \& Konold, T. R. (1999). Parenting Alliance Measure professional manual. Odessa, FL: Psychological Assessment Ressources.

Aspland, H., Llewelyn, S., Hardy, G. E., Barkham, M., \& Stiles, W. (2008). Alliance ruptures and rupture resolution in cognitive-behavior therapy: A preliminary task analysis. Psychotherapy Research, 18, 699-710. doi:10.1080/10503300802291463

Barton, A. W., Beach, S. R. H., Kogan, S. M., Stanley, S. M., Fincham, F. D., Hurt, T. R., \& Brody, G. H. (2015). Prevention effects on trajectories of African American adolescents' exposure to interparental conflict and depressive symptoms. Journal of Family Psychology, 29, 171-179. doi:10.1037/fam0000073

Benson, L. A., McGinn, M. M., \& Christensen, A. (2012). Common principles of couple therapy. Behav Ther, 43(1), 25-35. doi:10.1016/j.beth.2010.12.009

Bodenmann, G. (2008). Dyadisches Coping Inventar: Testmanual. Bern, Switzerland: Huber.

Bonds, D. D., \& Gondoli, D. D. (2007). Examining the process by wich marital adjustment affects maternal warmth: The role of coparenting support as a mediator. Journal of Family Psychology, 21, 288-296. doi:10.1037/0893-3200.21.2.288

Bowen, M. (1984). La différenciation du soi. Paris: ESF.

Bradley, B., \& Furrow, J. (2007). Inside blamer softening: Maps and missteps. Journal of Systemic Therapies, 26, 25-43. doi:10.1521/jsyt.2007.26.4.25

Bray, J. H., Williamson, D. S., \& Malone, P. E. (1984). Manual for the Personal Authority in the Family System Questionnaire. Houston, TX: Houston Family Institute.

Buehlman, K. T., Gottman, J. M., \& Katz, L. F. (1992). How a couple views their past predicts their future: Predicting divorce from an oral history interview. Journal of Family Psychology, 5(3), 295-318. 
Carneiro, C., Vaudan, C., Duc-Marwood, A., Darwiche, J., de Roten, Y., \& Despland, J.-N. (2012). Manuel psychothérapeutique: L'intervention systémique brève intégrative. Département de psychiatrie Centre hospitalier universitaire vaudois.

Christopher, C., Umemura, T., Mann, T., Jacobvitz, D. B., \& Hazen, N. L. (2015). Marital quality over the transition to parenthood as a predictor of coparenting. Journal of Child and Family Studies, 24(12), 3636-3651.

Durtschi, J., Soloski, K. L., \& Kimmes, J. (2017). The dyadic effects of supportive coparenting and parental stress on relationship quality across the transition to parenthood. Journal of Marital \& Family Therapy, 43, 308-321. doi:10.1111/jmft.12194

Epstein, N. B., Baldwin, L. M., \& Bishop, D. S. (1983). The McMaster Family Assessment Device. J Marital Fam Ther, 9(2), 171-180.

Favez, N. (2013). Les relations de couple: constitution et évolution. In N. Favez (Ed.), L'examen clinique du couple: Théories et instruments d'évaluation (pp. 11- 40). Bruxelles, Belgique: Mardaga.

Favez, N., \& Frascarolo, F. (2013). Le coparentage : Composants, implications et thérapie. Devenir, 25(2), 73. doi:10.3917/dev.132.0073

Feinberg, M. E., Jones, D. E., Hostetler, M. L., Roettger, M. E., Paul, I. M., \& Ehrenthal, D. B. (2016). Couple-focused prevention at the transition to parenthood a randomized trial: Effects on coparenting, parenting, family violence, and parent and child adjustment. Prevention Science, 17, 751-764. doi:10.1007/s11121-016-0674-z

Fergus, K., \& Skerrett, K. (2015). Resilient couple coping revisited: Building relationship muscle. In K. Skerrett \& K. Fergus (Eds.), Couple resilience: Emerging perspectives (pp. 199-210). NY: Springer.

Florsheim, P., Burrow-Sanchez, J. J., Minami, T., McArthur, L., Heavin, S., \& Hudak, C. (2012). Young parenthood program: Supporting positive paternal engagement through 
coparenting counseling. American Journal of Public Health, 102, 1886-1892. doi:10.2105/AJPH.2012.300902

Greenberg, L. S. (2007). A guide to conducting a task analysis of psychotherapeutic change. Psychotherapy Research, 17(1), 15-30. doi:10.1080/10503300600720390

Haley, J. (1963). Strategies of psychoterapy. New York: Grune and Stratton.

Heatherington, L., \& Friedlander, M. L. (1990). Applying task analysis to structural family therapy. Journal of Family Psychology, 4(1), 36-48.

Heatherington, L., \& Friedlander, M. L. (2007). Manifestations and facilitation of insight in couple and family therapy. In L. G. Castonguay \& C. E. Hill (Eds.), Insight in Psychotherapy. Washington, DC: American Psychological Association.

Kitzmann, K. M. (2000). Effects of marital conflict on subsequent triadic family interactions and parenting. Developmental psychology, 36(1), 3-13. doi:10.1037//0012-1649.36.1.3

Koren-Karie, N., Oppenheim, D., Dolev, S., Sher, E., \& Etzion-Carasso, A. (2002). Mothers' insightfulness regarding their infants' internal experience: Relations with maternal sensitivity and infant attachment. Developmental psychology, 38(4), 534-542. doi:10.1037//0012-1649.38.4.534

Lambert, M. J., Fintch, A. E., Okishi, J., \& Reisinger, C. W. (2005). Administration and scoring manual OQ-10.2: Adult outcome questionnaire for screening individuals and population monitoring. OQ Measures LLC. American Professional Credentialing Services.

Marcu, I., Oppenheim, D., \& Koren-Karie, N. (2016). Parental insightfulness is associated with cooperative interactions in families with toddlers. Journal of Family Psychology, 30(8), 927-934. doi:10.1037/fam0000240 
McAleavey, A. A., \& Castonguay, L. G. (2014). Insight as a common and specific impact of psychotherapy: therapist-reported exploratory, directive, and common factor interventions. Psychotherapy, 51, 283-294. doi:10.1037/a0032410

McCarty, C., \& Doyle, S. (2001). Parent child communication. Retrieved from www.fasttrackproject.org

Minuchin, S. (1974). Families and family therapy. Oxford, England: Harvard University Press.

Morrill, M. I., Hines, D. A., Mahmood, S., \& Cordova, J. V. (2010). Pathways between marriage and parenting for wives and husbands: The role of coparenting. Family Process, 49, 59-73. doi:10.1111/j.1545-5300.2010.01308.x

Oppenheim, D., Goldsmith, D., \& Koren-Karie, N. (2004). Maternal insightfulness and preschoolers' emotion and behavior problems: Reciprocal influences in a therapeutic preschool program. Infant Mental Health Journal, 25(4), 352-367. doi:10.1002/imhj.20010

Oppenheim, D., \& Koren-Karie, N. (2002). Mothers' insightfulness regarding their children's internal worlds: the capacity underlying secure child-mother relationships Infant Mental Health Journal, 23(6), 593-605. doi:10.1002/imhj.10035

Pascual-Leone, A., Greenberg, L. S., \& Pascual-Leone, J. (2014). Task analysis: New developments for programmatic research on the process of change. In W. Lutz \& S. Knox (Eds.), Quantitative and qualitative methods in psychotherapy research (pp. 249272). New York: Routledge.

Pedro, M. F., Ribeiro, T., \& Shelton, K. H. (2012). Marital satisfaction and partners' parenting practices: The mediating role of coparenting behavior. Journal of Family Psychology, 26, 509-522. doi:10.1037/a0029121

Reid, D. W., Dalton, E. J., Laderoute, K., Doell, F. K., \& Nguyen, T. (2006). Therapeutically induced changes in couple identity: The role of We-ness and interpersonal processing 
in relationship satisfaction. Genetic, Social, and General Psychology Monographs, 132(3), 241-284. doi:10.3200/MONO.132.3.241-288

Schoppe-Sullivan, S. J., Mangelsdorf, S. C., Frosch, C. A., \& McHale, J. L. (2004). Associations between coparenting and marital behavior from infancy to the preschool years. Journal of Family Psychology, 18, 194-207. doi:10.1037/0893-3200.18.1.194

Seider, B. H., Hirschberger, G., Nelson, K. L., \& Levenson, R. W. (2009). We can work it out: Age differences in relational pronouns, physiology, and behavior in marital conflict. Psychology and Aging, 24(3), 604-613. doi:10.1037/a0016950

Selvini, M. (1987). Histoire d'une recherche : le travail thérapeutique de Mara SelviniPalazzoli. Paris: ESF.

Skerrett, K. (2015). Resilience in couples: A view of the landscape. In K. Skerrett \& K. Fergus (Eds.), Couple resilience: Emerging perspectives (pp. 3-22). NY: Springer.

Spanier, G. B. (1976). Measuring dyadic adjustment: New scales for assessing the quality of marriage and similar dyads. Journal of Marriage and the Family, 38(1), 15-28.

Spielberger, C. D., Gorsuch, R. L., Lushene, R. E., Vagg, P. R., \& Jacobs, G. A. (1983). Manual for the state-trait anxiety inventory. Consulting Psychologists.

Spitzer, R. L., Kroenke, K., Williams, J. B. W., \& Group, P. H. Q. P. C. S. (1999). Validation and utility of a self-report version of PRIME-MD: The PHQ primary care study. Journal of American Medical Association, 282(18), 1737-1744.

Strigth, A. D., \& Bales, S. S. (2003). Coparenting quality: Contributions of child and parent characteristics. Family relations, 52, 232-240. doi:10.1111/j.1741-3729.2003.00232.x

Stroud, C. B., Meyers, K. M., Wilson, S., \& Durbin, C. E. (2015). Marital quality spillover and young children's adjustment: Evidence for dyadic and triadic parenting as mechanisms. Journal of Clinical Child \& Adolescent Psychology, 44(5), 800-813. doi:10.1080/15374416.2014.900720 
Talbot, J. A., \& McHale, J. P. (2004). Individual parental adjustment moderates the relationship between marital and coparenting quality. Journal of Adult Development, 11, 191-205. doi:10.1023/B:JADE.0000035627.26870.f8.

Teubert, D., \& Pinquart, M. (2011). The coparenting inventory for parents and adolescents (CIPA): Reliability and Validity. European Journal of Psychological Assessment, 27(3), 206-215. doi:10.1027/1015-5759/a000068

Timulak, L. (2007). Identifying core categories of client-identified impact of helpful events in psychotherapy: A qualitative meta-analysis. Psychotherapy Research, 17, 305-314. doi:10.1080/10503300600608116

Wampold, B. E., Imel, Z. E., Bhati, K. S., \& Johnson-Jennings, M. D. (2007). Insight as a common factor. In L. G. Castonguay \& C. E. Hill (Eds.), Insight in Psychotherapy. Washington, DC: American Psychological Association.

Woldarsky Meneses, C., \& Greenberg, L. S. (2011). The construction of a model of the process of couples' forgiveness in emotion-focused therapy for couples. Journal of Marital \& Family Therapy, 37, 491-502. doi:10.1111/j.1752-0606.2011.00234.x

Zemp, M., Johnson, M. D., \& Bodenmann, G. (2018). Within-family processes: Interparental and coparenting conflict and child adjustment. Journal of Family Psychology, 32, 299309. doi:10.1037/fam0000368

Zuccarini, D., Johnson, S. M., Dalgleish, T. L., \& Makinen, J. A. (2013). Forgiveness and reconciliation in emotionally focused therapy for couples: the client change process and therapist interventions. Journal of Marital \& Family Therapy, 39, 148-162. doi:10.1111/j.1752-0606.2012.00287.x 